In Memoriam

\title{
IN MEMORIAM PROFESOR MARIO SILVA GARCÍA
}

\section{IN MEMORIAM PROFESSOR MARIO SILVA GARCÍA}

Pinto este retrato con algunos rasgos salientes del pensamiento, afinidades electivas y vida que encuentro en un rápido recorrido por la historia de la filosofía.

María Noel Lapoujade *

Evoco una frase: "Hombre soy: nada de lo humano me es ajeno". Terencio Africano (194 aC). Retrato de Silva. ${ }^{1}$. Eckhart de Hohenheim (1260) ha dejado de ser Eckhart, para convertirse en el actual Meister Eckhart. Meister Eckhart, Suso y Tauler crean un nuevo tipo en el mundo medieval: el de un "Maestro de Lectura" (Lesemeister) que fuera también y en primer lugar un "Maestro de Vida" (Lebemeister). ${ }^{2}$ Me refiero a Silva García, Maestro de Lectura y Maestro de Vida.

Silva García, encarnación del renacentista hombre universal, siendo un hombre singular, hombre único. Espíritu singular, único, en su universalidad. ${ }^{3}$ ¿A qué universalidad me refiero?. A todas las posibles. Universalidad de los conocimientos, erudición. Universalidad que desborda la erudición: sabiduría. Universalidad de perspectivas, miradas a la lejanía, que supo volver próxima e íntima. Su pensamiento es universal, es decir, abierto, libre, en su vaivén eterno de la inmanencia a la trascendencia, y su retorno a la inmanencia, "el camino hacia arriba y hacia abajo es uno y el mismo" enseña Heráclito (siglo VI a.C), y retoman los alquimistas, a quienes también conocía profundamente. ${ }^{4}$

Silva, como Descartes, sabe de sueños reveladores de filosofías. Sabe de la racionalidad lúcida, como Silva encarnando a Monsieur Teste de Paul Valéry poesía y prosa que corría por sus venas. Pero Silva, Monsieur Teste se levanta con esfuerzos, en un larguísimo camino, de la oscuridad a la luz, de lo inconsciente freudiano, y sobre todo junguiano a la luz de la conciencia. ${ }^{5}$

Silva sale al mundo, de la mano de Rilke, poeta de sus desvelos, quien afirmaba que "el animal y el niño están en el mundo, el hombre está ante el mundo. El romanticismo alemán y francés describen con belleza este vaivén eterno de Silva hombre, Silva filósofo. Novalis nos muestra que Silva vive la filosofía en la caricia, intensidades compartidas con Gaston Bachelard por su amor a la inmediatez. Con Goethe Silva vive el "mundo como un enjambre de símbolos", pero también vive las correspondencias baudelerianas del mundo, que el francés canta en sus Poemas en Prosa.

Silva hombre, se levanta paulatinamente, de "la noche oscura del alma" de San Juan de la Cruz, de la materia informe, nigredo alquímico, de la muerte en el alma, hacia su insaciable búsqueda de la forma. Es la transmutación apolínea de Dioniso, el camino a la luz diurna vital. Camino arduo, sembrado de espinas, en el que cae y levanta más de una vez. Silva evoca a Paul Valéry, prolongado y recreado en su filosofía pudorosa que asoma como preguntas. Silva exclama en un pasaje esencial a su concepción de la vida:

Paul Valéry confiesa la necesidad de empezar el ascenso desde la oscuridad, desde el germen, pero el movimiento va hacia la forma élancée, donde el impulso, el élan domina. ... ¿No declara Hugo que "toda planta es una lámpara y el perfume su luz"? ¿Y Balzac, que todo perfume es una combinación de aire y de luz? ¿No ha llegado el momento de buscar correspondencias por lo alto? ¿No es esa la forma de operar la sublimación del querer, del querer oscuro del crecimiento que se eleva, estalla y quiere volver a ser querer bajo la especie innumerable y ligera de las simientes. Voluntad sombría, voluntad diáfana, unidad profunda vista con la claridad en la cual los perfumes, los colores y los sonidos se responden. ${ }^{6}$

Nuestro Maestro de Vida, ama. Bajo su imagen adusta, late un espíritu sediento de amor, de ternura materna. De ahí la hondura de su valoración de la mano, el tacto, metamorfoseado en una "metafísica de la caricia". En unas páginas magistrales, entre miles de otras páginas magistrales leo: La caricia supone la sensibilidad, pero la trasciende. No hay un asir; solicita aquello que se evade sin cesar, ... , lo que aún no se posee. Busca, persigue lo intangible. Expresa el amor, aquel que no puede volcarse en palabras. Mucho más elocuente que el discurso,... se orienta más allá de lo dado, a lo que se presiente, a lo que se adivina.

\footnotetext{
1 Publio Terencio Africano, (s.f.) Heautontimoroumenos, El atormentador de sí mismo.

2 Alain de Libera, Eckhart, (1999) Suso, Tauler y la divinización del hombre, Barcelona.:J.J.de Olañeta,

3 Burckhardt, Jackob (1964). La cultura del Renacimiento en Italia. Barcelona: Iberia,

4 Héraclite,(1964). Fragments, Les penseurs grecs avant Socrate. De Thalès de Milet à Prodicos. Paris: Flammarion.

5 Valéry, Paul (1957). Monsieur Teste, Oeuvres Complètes, Paris : Gallimard,

6 .Silva García, Mario A, (1999). Avatares de la imaginación, en Espacios Imaginarios, Ma. Noel Lapoujade, F F y L, UNAM.
} 
Y como lenguaje ante las grandes cosas, tropieza con lo inefable, la caricia va a la búsqueda de lo intangible. ${ }^{7}$

Silva, con la refinada sensibilidad del tímido, convierte su impulso insaciable de sabiduría, de amor, de vida en su pensamiento, vibrante de poesía, contenido en el murmullo suave de una belleza pudorosa. La docta ignorancia en Silva se transmuta su pudor filosófico. De ahí que en Silva vemos el hombre como el "ser entreabierto" de Gaston Bachelard. ${ }^{8}$ Silva-Bachelard, unidos por la correspondencia epistolar que tuve la fortuna de conocer, comparten profundidades del alma humana: epistemólogos, saben de los procesos de evaporación. Escudriñan ambos las transmutaciones materiales-espirituales de los alquimistas, en sus universos simbólicos. Observan insaciables todo lo humano, en particular su mente, su racionalidad, su imaginación, los sentimientos, los deseos, los instintos, pero además estudian el sistema nervioso central, y tanto más. Pero su sed insaciable los impulsa a la búsqueda de un ser humano más completo, integral, aquél en que late el arte, la pintura, la poesía, la música, que aman con intensidad. Así construyen poéticas que los habitan. Sienten ambos la belleza, la estética corre por sus venas. ${ }^{9}$

Espíritus faros de nuestro tiempo, uno en Francia, otro en Uruguay, se afanan ambos en la búsqueda de lo sutil químico-alquímico-poético, vía a la trascendencia. Por eso, ambos comparten su admiración por Reiner-María Rilke. Evoco a Bachelard; sé que Silva en este instante me aprueba y me sonríe. Bachelard recuerda a Rilke buscando en el corazón de la rosa, un cuerpo de suave intimidad. Dice Rilke:

Qué cielos se reflejan ahí

en el lago interior

de estas rosas abiertas.

Bachelard responde:

Todo el cielo se sostiene en el espacio de una rosa.

El mundo viene a vivir en un perfume. ${ }^{10}$ La vía sutil a la trascendencia despunta en el perfume de la rosa de Angelus Silesius: ¿Por qué florece la rosa? La rosa florece sin por qué. ${ }^{11}$

Esta rosa, como el canto del pájaro, regala su belleza desinteresadamente, la plenitud se envuelve en la belleza de su perfume y su armonía.

Silva, el bíblico "alfarero de su propia arcilla" transmutó su vida en una ofrenda. Silva, el artista de sí mismo, como pide Pico de la Mirandola, ${ }^{12}$ hizo de su vida una gran obra que, como todo arte, se prodiga como un don.

Recibimos con gratitud este don, para transmitirlo a otros espíritus en abierta disponibilidad.

\footnotetext{
* María Noel Lapoujade, uruguaya, Posgrado en Filosofía en la U. de Heidelberg, Alemania, con beca del DAAD. Dos doctorados en Filosofia, por la UNAM, México y por U. de París, Francia. Dos Posdoctorados en Filosofía Francesa Contemporánea en la U. de Paris, con becas de la UNAM.

Profesora titular full time de Posgrado y Grado en Filosofía (UNAM, 1975 a la fecha). Cursos y conferencias en Brasil, Cuba, Costa Rica, Chile, Colombia, México, Uruguay, Argentina, Paraguay; en Francia, en la U. de Paris y en la $U$. de Bourgogne.

Investigadora en el Centre Gaston Bachelard de la U. de Bourgogne, Francia (2003-05).

Fundadora del Centro Interdisciplinario de Estudios sobre lo Imaginario y la Racionalidad y del Seminario interdisciplinario de investigación sobre lo imaginario (UNAM); del Programa interdisciplinario de investigación sobre la Imaginación, lo Imaginario y la Racionalidad, PROIM. Fundadora de la Maestría en Estética y Artes, U. de Puebla, México.

Premios: "Norman Sverdlin" y Medalla Gabino Barreda, por la UNAM. Condecorada "La Dama de las Hespérides", por el Ateneo de Murcia., España.

Es corresponsal en México de la Revista Relaciones (Montevideo). Pertence a los Comités Editoriales de las Revistas: Signos - U. A. M.-Iztapalapa, México-; Península de Mérida, Yucatán.

Múltiples libros y artículos publicados en Francia, Alemania, Italia, Bulgaria, Rumania, Estados Unidos, México, Costa Rica, Brasil, Venezuela, San Salvador y Uruguay. Traducida al inglés, del francés al portugués, al rumano, al búlgaro, al italiano.

Incluida como filósofa latinoamericana del siglo XX en el Biographical Dictionary of Twentieth Century Philosophers, publicado por la Routledge Editorial en Londres y New York. Incluida como filósofa lationamericana en Identidad, Integración y Creación cultura en América Latina, editada por la UNESCO.
}

\footnotetext{
7 Silva García, Mario A.(1989). Aproximación al mundo de la forma, Abato, 3, Inst. Jung de Buenos Aires. Montevideo. 8 Lapoujade, María Noel (1992). Silva García: un filosofar itinerante, Revista Relaciones, N 96.

9 Bachelard, Gaston (1957). La poétique de l'espace, Paris: P.U.F.,

10 Lapoujade, María Noel (2011). Diálogo con Gaston Bachelard acerca de la poética, Mérida: Universidad Nacional Autónoma de México.

11 Angelus Silesius, (1997) Le pèlerin chérubinique. Paris: Editions du Cerf.

12 Pico della Mirandola, G. (1993). De la dignité de l'homme, France: Editions de L'Éclat.
} 